\title{
Endoscopic endonasal dacryocystorhinostomy: experience in a rural turtiary care hospital
}

\author{
Ganesh Chandra Gayen ${ }^{1}$, Kanika Mandi Chowdhury ${ }^{2}$, Ritam Ray ${ }^{3}$ \\ 1. Assistant professor, Dept. of ENT, Burdwan Medical College \& Hospital, \\ P.O. - Rajbati, Burdwan - 713104, West Bengal, India
}

2. Assistant professor, Assistant secretary, Dept. of Health \& Family welfare, Govt of West Bengal, Swasthya Bhawan, GN-29, Sector - 5, Salt Lake City, Kolkata-700091, West Bengal, India

3. RMO-cum-clinical tutor, Dept. of ENT, Burdwan Medical College \& Hospital, P.O. - Rajbati, Burdwan - 713104, West Bengal, India

Corresponding Author: Dr Ritam Ray

\begin{abstract}
Objective: To study the outcome of endoscopic endonasal dacryocystorhinostomy in our hospital.Methods:

Design: Prospective Study

Setting: Tertiary rural government teaching hospital

Participants: 40 patients with chronic dacryocyctitis with nasolacrymal duct obstruction over a period of 2 years from January, 2010 to December, 2012 who attended in ENT outpatient department of Burdwan Medical College \& Hospital were included in this study.

Results: Females are more affected than male. After 6 months, 5 patients (12.5\%) presented with complete stenosis, 3 patients (7.5\%) presented with partial stenosis of stoma and in 32 patients (80\%) sac stoma was completely patent. Complications include bleeding, postoperative cellulitis of the lower eye lid, granulation tissue around the stoma, synechia inside nasal cavity and stenosis of the stoma etc.

Conclusion: Endoscopic dacryocystorhinostomy is the preferred treatment in Chronic dacryosystitis with nasolacrymal duct obstruction. There are so many advantages of endoscopic dacryocystorhinostomy over the external dacryocystorhinostomy. Regular follow-up is necessary in the post operative period.
\end{abstract}

KEYWORDS: Chronic dacryocystitis; endoscopic dacryocystorhinostomy; external dacryocystorhinostomy;

\section{INTRODUCTION}

Dacryocystorhinostomy is a surgical procedure by which the lacrymal flow is diverted into the nasal cavity by making an opening in the lacrymal sac when the nasolacrymal duct gets blocked. The operation can be carried out using either an external or endonasal surgical approach. Adeo Toti originally described the traditional external approach in 1904 [1]. The original intranasal approach was described by Caldwell [2] in 1883. McDonogh \& Meiring [3] described the first modern endonasal dacryocystorhinostomy procedure in 1989. Endoscopic dacryocystorhinostomy has been gaining popularity, largely due to technological advances in endoscopes and other modern instruments of rhinologic surgery.

\section{MATERIALS AND METHODS}

This study was carried out in the Dept of ENT, Burdwan Medical College \& Hospital, Burdwan. It comprises of 40 patients with chronic dacryocystitis who attended ENT out patient department of Burdwan Medical College \& Hospital over a period of 2 years from January, 2010 to December, 2012. Detailed history was taken and the patients were examined carefully after admission. Lacrymal sac syringing done in all cases under topical anaesthesia to identify the level of obstruction. Diagnostic nasal endoscopy was done in all cases preoperatively to exclude any pathology inside nasal cavity and need for additional surgery like septoplasty etc.

\subsection{Inclusion criteria:}

[1] ASA grade I and II patients

[2] Both males and females

[3] Adult patients aged 20 to 60 years of age

[4] Patients with chronic dacryocystitis with unilateral nasolacrymal duct obstruction 


\subsection{Exclusion criteria:}

[1] Patients with bleeding and clotting disorder

[2] Any pathology inside nasal cavity other than deviated nasal septum

[3] Chronic dacryocystitis with obstruction proximal to the lachrymal sac

[4] Bilateral chronic dacryocystitis

[5] Patients without fulfilment of inclusion criteria

[6] Patients not consenting for operation under local anaesthesia

[7] lack of valid consent

[8] Uncontrolled medical disease

All the cases $(n=40)$ were operated under local anesthesia with premedication (Pentazocine, Atropine, Promethazine). Nasal cavity was packed with cotton pledgets soaked in $4 \%$ lignocaine with 1:40,000 adrenaline half an hour before the starting the procedure. $4 \mathrm{~mm} 0^{\circ}$ hopkins rod endoscope (Karl Storz) with camera and monitor was used in all cases. The mucosa of the lateral nasal wall in the region of the maxillary line, over the axilla and the anterior face of middle turbinate were infiltrated with $2 \%$ lignocaine with adrenaline $(1: 1,00,000)$.

An U-shaped flap was created based on the uncinate process with the help of sickle knife and it is hinged posteriorly. The tough bone of frontal process of maxilla overlying the lachrymal sac was removed using a $2 \mathrm{~mm}$ karrison's punch forceps and the lachrymal sac was properly exposed. Then the periosteum over the sac was removed. The medial wall of the lacrimal sac was tented with the bowman's lacrimal probe and vertical incision was given in the sac wall from top to bottom so that the common canalicular opening can be easily seen.. Then with the help of a right angle pick, two flaps were created so that the medial wall of the sac gets opened like a book. Now the nasal mucosa was refashioned and placed in the lateral nasal wall in such a way that it will cover the raw bony lateral wall without blocking the large opening of the sac. Finally, merocele nasal pack was carefully placed in nasal cavity to keep the mucosal flap anastomosis in position and proper haemostasis. Nasal pack was removed after 4 days.

Lacrymal sac syringing was done in weekly interval for 6 weeks under endoscopic control. Patients were followed up for 6 months. At each follow-up regular nasal endoscopic examinations were performed to assess the wound healing and to remove crusts and granulations. Lacrimal sac syringing was done to confirm the patency of ostium. If during followup, we found any obstruction in the lachrymal pathway or patient complaints of continued watering from the eye, it was considered as a surgical failure.

Data was tabulated and analysed manually.

\section{RESULTS}

40 patients were taken up for endoscopic dacryocystorhinostomy during the period of January, 2010 to December, 2012 in the dept. of ENT, Burdwan Medical College \& Hospital, Burdwan. Out of these patients, 13 patients were male and 27 patients were female. All patients were adult with age range between 20 to 60 years. 16 patients had associated deviation of septum out of which 9 patients required endoscopic septoplasty prior to sac surgery to gain access to the sac area.

During follow-up, we found that after three months, 2 patients (5\%) had partial stenosis, 3 patients (7.5\%) had complete stenosis and rest 35 patients $(87.5 \%)$ had completely patent sac stoma. But after 6 months, 5 patients (12.5\%) presented with complete stenosis,

3 patients $(7.5 \%)$ presented with partial stenosis and in 32 patients $(80 \%)$ sac stoma was completely patent (Table 1).19 patients (47.5\%) presented with complications and they were managed accordingly. 4 patients $(10.5 \%)$ presented with bleeding who were managed conservatively. 1 patient $(2.5 \%)$ presented with postoperative cellulitis of the lower eye lid which was also responded with oral antibiotics and antiinflammatory agents. 4 patients (10\%) developed granulation tissue around the stoma which was removed during the follow-up endoscopic cleaning. 2 patients $(5 \%)$ presented with synechia inside nasal cavity which was resected during followup. 3 patients (7.5\%) had partial stenosis of stoma after 6 months follow-up. On sac syringing, there was free flow of water. 5 patients end up with complete stenosis of stoma after 6 months (Table 2). But the refused the option of revision surgery. 


\section{DISCUSSION}

3 to $4 \%$ of patients attending the ophthalmology clinics, complaint of excessive tearing [4] of which chronic dacryocystitis is one of the commonest cause. Chronic infection of lachrymal sac due to pathway obstruction leads to outlet obstruction and overflow of tear. External dacryocystorhinostomy was the standard surgical approach previously. But since the advent of endonasal endoscopic dacryocystorhinostomy, the popularity of external dacryocystorhinostomy is dramatically reduced as there are certain definite advantage are there in endoscopic dacryocystorhinostomy.

The failure rate of external dacryocystorhinostomy is in between $3-15 \%$ [5]. But in endonasal endoscopic dacryocystorhinostomy success rate is higher. It directly access to the sac through the lacrimal bone, avoiding double-side dissection of the sac and is less traumatic, thus, it shortens the hospital stay. The facial scar is avoided and it preserves the lacrimal pump function. Even in case of acute dacryocystitis, we can go for endoscopic dacryocystorhinostomy where external dacryocystorhinostomy is contraindicated.

In our study, we have found a females predominance with a male female ratio 1: 2.07 which is almost comparable with Yung \& Hardman [6]. Our success rate in this study is $87.5 \%$ which can be compared with other studies. Literature review shows that the success rate of endoscopic dacryocystorhinostomy varies between 82 to $95 \%$ [6-9].

Success in endoscopic dacryocystorhinostomy mostly depend on adequate bone work and wide removal of frontal process of maxilla. Stoma should be wide enough (Fig.I) and common canalicular opening should be visible. Adequate post operative follow-up is also necessary.

Complications of endoscopic dacryocystorhinostomy include stenosis of the stoma, bleeding from the nasal cavity, orbital injury, CSF leakage through a fractured ethmoid, and corneal abrasion, synechia inside nasal cavity and infection [10]. There may be formation granulation tissue around the stoma.

Before going for endoscopic dacryocystorhinostomy, we have to be sure that the level of obstruction is at nasolacrymal duct level. Common canalicular blockage is very difficult to manage and rate of complications is also higher. We should also examine the nasal cavity properly to exclude other separate pathologies. Septal deviation should be corrected, if any.

\section{TABLES}

TABLE - 1

Patency of sac opening during sac syringing

\begin{tabular}{|l|l|l|}
\hline Nasolacrymal fistula & $\mathbf{3}$ months & $\mathbf{6}$ months \\
\hline Completely patent & $\mathbf{3 5}(\mathbf{8 7 . 5 \% )}$ & $\mathbf{3 2}(\mathbf{8 0} \%)$ \\
\hline Partially patent & $\mathbf{2}(5 \%)$ & $\mathbf{3}(7.5 \%)$ \\
\hline Complete obstruction & $\mathbf{3}(7.5 \%)$ & $\mathbf{5 ( 1 2 . 5 \% )}$ \\
\hline
\end{tabular}

TABLE - 2

\begin{tabular}{|l|l|}
\multicolumn{1}{l}{ Complications of surgery } \\
\hline Complications & No of cases $(\mathrm{n}=40)$ \\
\hline No complication & $21(52.5 \%)$ \\
\hline Bleeding & $4(10 \%)$ \\
\hline Cellulitis & $1(2.5 \%)$ \\
\hline Granulation around the stoma & $4(10 \%)$ \\
\hline Synechia & $2(5 \%)$ \\
\hline Partial stenosis & $3(7.5 \%)$ \\
\hline Complete stenosis & $5(12.5 \%)$ \\
\hline
\end{tabular}

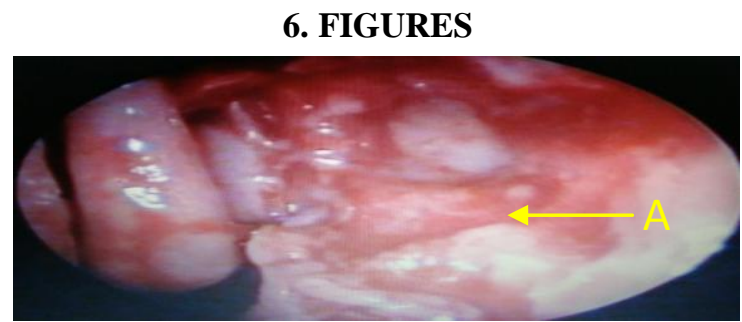

Figure I : Intraoperative picture showing a wide rhinostoma (A). 


\section{CONCLUSION}

Endoscopic dacryocystorhinostomy is the preferred treatment in Chronic dacryosystitis with nasolacrymal duct obstruction. There are so many advantages of endoscopic dacryocystorhinostomy over the external dacryocystorhinostomy. Regular follow-up is necessary in the post operative period.

\section{REFERENCES}

[1] Toti A (1904) Nuovo methodo conservatore di cura radicale delle suppurazioni croniche del sacco lacrimale(Dacriocistor inostomia). Clin Mod Firenze 10:385-387

[2] Caldwell GW (1893) Two new operations for obstruction of the nasal duct. N Y Med J 57:581-582

[3] Mc Donogh M, Meiring JH (1989) Endoscopic transnasal dacryocystorhinostomy. J Laryngol Otol; 103:585-7

[4] Welham RA (1997) Clinical ophthalmology. Miller S Ed, IOP Publishing Ltd: Bristol (Indian Edn); 391-441

[5] Metson R (1990) The endoscopic approach for revision DCR. Laryngoscope 100:1344-1347

[6] Yung MN, Hardman Lea S (2002) Analysis of the results of surgical endoscopic dacryocystorhinostomy: Effect of the level of obstruction. Br J Ophthalmol 86(7):792-794

[7] Mangal S, Vimal J, Gupta SC (2004) Intranasal Endoscopic DCR (END-DCR) in cases of dacryocystitis. Indian Journal of Otolaryngology and Head and Neck surgery 56(3):177-183

[8] Mortimre S, Banhegy GY, Lancaster JL (1999) Endoscopic DCR without silicon stenting. J R Coll Syrg Edinb 44:371-373

[9] Wormald PJ (2002) Powered endoscopic dacryocystorhinostomy 112(1):69-72

[10] Fayet B, Racy E, Assouline M. Complications of standardized endonasal dacryocystorhinostomy with unciformectomy. Ophthalmology. 2004;111:837-845. 